\title{
Custo de produção de rações alternativas para peixes onívoros no estado do Pará, Amazônia, Brasil
}

\section{Production Cost of alternative feed for omnivorous fish in the state of Pará, Amazonia, Brazil}

Marcos Ferreira Brabo

Universidade Federal do Pará

E-mail: mbrabo@ufpa.br

OrclD: https://orcid.org/0000-0001-8179-9886

Ana Raquel Leite da Silva Instituto Federal de Educação, Ciência e Tecnologia do Pará

E-mail: ana.raquelleite@hotmail.com

OrcID: https://orcid.org/0000-0002-3157-9284

Kaio Diego das Neves Barros

Universidade Federal Rural da Amazônia

E-mail: kaio.diegobarros@gmail.com

OrcID: https://orcid.org/0000-0002-3894-2189

Renato Pinheiro Rodrigues

Universidade Federal do Pará

E-mail: renatopinheiros4@gmail.com

OrcID: https://orcid.org/0000-0003-2596-2807

Daniel Abreu Vasconcelos Campelo

Universidade Federal do Pará

E-mail: danielvc@ufpa.br

OrcID: https://orcid.org/0000-0001-9204-3566

Galileu Crovatto Veras Universidade Federal do Pará

E-mail: galiveras@hotmail.com

OrclD: https://orcid.org/0000-0002-9975-830X

Resumo: Avaliou-se o custo de produção de ração alternativa para peixes onívoros. As informações sobre ingredientes e preços (varejo) foram obtidas mensalmente de dezembro/2014 a novembro/2015 em Belém, Santa Izabel do Pará, Castanhal, Santa Maria do Pará e Bragança. Posteriormente, foram formuladas rações e calculados os custos pela estrutura de custo operacional. O processamento considerou quatro etapas, desde a "mistura" ao "resfriamento", e tudo obedeceu a demanda hipotética de piscicultura em viveiro escavado com 0,2 hectares de lâmina d'água. Constatou-se que a maioria dos ingredientes estiveram disponíveis ao longo do ciclo de produção e outros apresentaram sazonalidade. As rações formuladas tiveram de 28 a $45 \%$ de proteína bruta e custo de $\mathrm{R} \$ 1,88$ a $\mathrm{R} \$ 2,38$ por quilo, respectivamente. Houve baixo custo de produção, sugerindo menor preço de mercado se comparado aos preços praticados para rações industrializadas na região.

Palavras-chave: Aquicultura. Manejo alimentar. Nutrição de peixes.

Abstract: This study aimed to evaluate the producing cost of alternative feed for omnivorous fish. The information about ingredients and prices obtained monthly from December/2014 to November/2015 in Belém, Santa Izabel do Pará, Castanhal, Santa Maria do Pará and Bragança. Subsequently, rations formulated and costs calculated using the operating cost structure. The processing considered four stages, from "mixing" to "cooling", and everything followed a hypothetical demand for fish farming in a pond with 0.2 hectare of water 
area. It founded that most of the ingredients were available throughout the production cycle and others showed seasonality. The formulated diets had 28 to $45 \%$ crude protein and cost from $R \$ 1.88 / \mathrm{kg}$ to $R \$$ $2.38 / \mathrm{kg}$, respectively. There was a low production cost, suggesting a lower market price compared to the prices practiced for industrialized feed in the region.

Keywords: Aquaculture. Feed management. Fish nutrition.

Data de recebimento: $12 / 11 / 2019$

Data de aprovação: $23 / 11 / 2020$

DOI: https://doi.org/10.30612/agrarian.v14i51.10670

\section{Introdução}

A piscicultura é o ramo da aquicultura que trata da criação de peixes de água doce ou marinha e dispõe de sistemas de criação variados, possibilitando a adoção de distintas estratégias de criação, principalmente no tocante à dieta animal (Oliveira, 2015; Macedo \& Sipaúba-Tavares, 2018).

O desembolso com a aquisição de ração industrializada varia entre 50 e $80 \%$ em um ciclo produtivo na piscicultura e isto se deve ao custo que as indústrias fabricantes têm com a formulação, ingredientes, industrialização, controle de qualidade, custos administrativos, custos operacionais, encargos sociais e tributários e transporte, todos estes são fatores que elevam o preço das rações. Logo, torna-se fator limitante para a prática da atividade em empreendimentos de pequeno porte, induzindo a busca por alternativas de baixo custo, o que pode colocar em risco a qualidade produto final e, consequentemente, a viabilidade da produção (Ono, 1988; Brabo, Flexa, Veras, Paiva \& Fujimoto, 2013; Brabo et al., 2014).

Nesses casos é comum a oferta de rações alternativas compostas principalmente por subprodutos da agroindústria e pecuária devido ao baixo custo, ao volume e oferta contínua. Se por um lado oferece viabilidade ao rejeito como alimento, por outro pode prejudicar o desenvolvimento dos peixes por não atender as distintas exigências nutricionais que variam conforme a espécie, a idade e o ambiente, resultando em crescimento reduzido, perda de aptidão física, sistema imunológico deficiente e desenvolvimento de malformações corporais devido à subnutrição (Kubitza, 2009; Cyrino et al., 2010; Ribeiro, Melo, Costa, \& Teixeira, 2012).

Por isso, mesmo rações alternativas, é importante que os ingredientes sejam criteriosamente balanceados para que possa dispor de macro e micronutrientes suficientes para atender a demanda bioquímica, fisiológica e metabólica dos peixes. Apesar da relevância, os estudos sobre formulação de rações a partir de subprodutos para piscicultura e custos de produção são esparsos, com informações ainda pouco estabelecidas, principalmente em função da diversidade de hábitos alimentares e de quais subprodutos que podem ser utilizados como ingredientes na formulação de rações (Salaro, 2009; Ribeiro et al., 2012).

Portanto, o objetivo deste estudo foi avaliar o custo de produção de rações alternativas para peixes onívoros no Estado do Pará, considerando um processamento possível de ser efetuado em propriedade rural.

\section{Material e Métodos}

Entre dezembro/2014 e novembro/2015 foi realizado levantamento de informações sobre insumos e custos para a fabricação de ração alternativa peletizada, bem como preços de rações industrializadas do tipo extrusada comercializadas nos municípios de Belém, Santa Izabel do Pará, Castanhal, Santa Maria do Pará e Bragança. A formulação da ração seguiu protocolo de exigência nutricional de peixes onívoros para as fases "inicial", "engorda" e "terminação" com quatro teores de proteína bruta (PB) por meio de metodologia descrita por Furuya et al. (2010).

O custo de produção foi calculado pela estrutura de custo operacional adaptada de Matsunaga, Bemelmans e Toledo (1976) com os seguintes itens: (a) custo operacional efetivo (COE): somatório dos custos de contratação de mão-de-obra, aquisição de insumos, frete e manutenção dos equipamentos (desembolso efetivo); e (b) custo operacional total (COT): somatório do COE com a depreciação de bens de capital, que neste caso foi calculada pelo método linear. Foi considerado volume de produção de 5.000 $\mathrm{kg} / \mathrm{ano}$ e preços praticados em novembro/2015. 
Estes custos foram comparados com valores de rações industrializadas comercializadas na região, visando definir a conversão alimentar aceitável para os produtos elaborados. Este indicador foi estabelecido para cada tipo e total das rações formuladas a serem utilizadas ao longo do ciclo de produção pretendido.

Os parâmetros de produção considerados para simular a demanda de ração foram: estrutura de confinamento: viveiro escavado; espelho d'água: 0,2 ha; animal: tambaqui (Colossoma macropomum); peso inicial: 0,001 kg; peso final: $2 \mathrm{~kg}$; conversão alimentar de 2:1; densidade de estocagem: 0,5 peixe/ $\mathrm{m}^{2}$; ciclo de produção: 12 meses; taxa de mortalidade: 10\%; e produtividade: 0,9 kg/m²/ano (Izel \& Melo, 2004; Dairiki \& da Silva, 2011; Brabo et al., 2016) (Tabela 1).

Tabela 1. Parâmetros de produção hipotéticos para estimativa da demanda de ração industrializada.

\begin{tabular}{|c|c|c|c|c|c|c|c|c|c|c|}
\hline Mês & $\begin{array}{c}\mathrm{Pi} \\
(\mathrm{kg})\end{array}$ & $\begin{array}{c}\text { Pf } \\
(\mathrm{kg})\end{array}$ & $\begin{array}{c}\begin{array}{c}\text { Biom } \\
(\mathrm{kg})\end{array} \\
\end{array}$ & CAA/mês & CAA/fase & $\begin{array}{c}\text { Tipo de } \\
\text { Ração } \\
\end{array}$ & TDA & Freq & $\begin{array}{c}\text { QR acumulada } \\
(\mathrm{kg})\end{array}$ & $\begin{array}{c}\text { QR por tipo } \\
(\mathrm{kg})\end{array}$ \\
\hline 1 & 0,001 & 0,02 & 18 & 1,0 & 1,0 & $\begin{array}{l}\text { Farelada } \\
(45 \% \text { PB) }\end{array}$ & $10 \%$ & 4 & 18 & 18 \\
\hline $\begin{array}{l}2 \\
3\end{array}$ & $\begin{array}{l}0,02 \\
0,05\end{array}$ & $\begin{array}{l}0,05 \\
0,12\end{array}$ & $\begin{array}{l}45 \\
108\end{array}$ & $\begin{array}{l}1,2 \\
1,2\end{array}$ & 1,2 & $\begin{array}{l}2 \text { a } 4 \mathrm{~mm} \\
\text { (36\% PB) }\end{array}$ & $5 \%$ & 3 & $\begin{array}{c}54 \\
129,6\end{array}$ & 111,6 \\
\hline $\begin{array}{l}4 \\
5\end{array}$ & $\begin{array}{c}0,12 \\
0,2\end{array}$ & $\begin{array}{l}0,2 \\
0,3\end{array}$ & $\begin{array}{l}180 \\
270\end{array}$ & $\begin{array}{l}1,4 \\
1,5\end{array}$ & 1,7 & $\begin{array}{l}4 \text { a } 6 \mathrm{~mm} \\
(32 \% \mathrm{~PB})\end{array}$ & $3 \%$ & 3 & $\begin{array}{l}252 \\
405\end{array}$ & 275,4 \\
\hline 6 & 0,3 & 0,5 & 450 & 1,6 & & & & & 720 & \\
\hline 7 & 0,5 & 0,7 & 630 & 1,7 & & & & & 1.071 & \\
\hline 8 & 0,7 & 1 & 900 & 1,8 & & & & & 1.620 & \\
\hline 9 & 1 & 1,3 & 1.170 & 1,8 & 2,1 & 6 a $8 \mathrm{~mm}$ & $1 \%$ & 2 & 2.106 & 3.195 \\
\hline 10 & 1,3 & 1,55 & 1.395 & 1,9 & & & & & $2.650,5$ & \\
\hline 11 & 1,55 & 1,8 & 1.620 & 2,0 & & & & & 3.240 & \\
\hline 12 & 1,8 & 2 & 1.800 & 2,0 & & & & & 3.600 & \\
\hline
\end{tabular}

Pi: peso inicial; Pf: peso final; Biom: biomassa (valores ponderados pela mortalidade de 10\%); CAA/mês: conversão alimentar aparente por mês = consumo de ração/ganho em peso ao mês; CAA/fase: conversão alimentar aparente por fase de crescimento = QR por tipo/APeso da fase; Tipo de Ração: granulometria e proteína bruta (PB); TDA: taxa diária de arraçoamento por peso corporal; Freq: frequência = número de refeições ao dia; $Q R$ acumulada: Quantidade de ração acumulada = CAA/mês $\times$ Biom; $Q R$ por tipo: Quantidade de ração por tipo $=\sum$ (consumo de cada tipo de ração); Consumo de ração $=\mathrm{QR}$ acumulada do mês $-\mathrm{QR}$ acumulada do mês anterior. Fonte: Adaptado de Izel e Melo (2004); Dairiki e da Silva (2011); Brabo et al. (2016).

\section{Resultados}

As rações alternativas foram formuladas com as seguintes características de acordo com as exigências da espécie considerada: (1) fase inicial: ração farelada, 45\% PB e $3.400 \mathrm{kcal}$ ED/kg; (2) engorda: ração de 2 a $4 \mathrm{~mm}, 36 \%$ PB e $3.300 \mathrm{kcal}$ ED $/ \mathrm{kg}$, e ração de 4 a 6 mm, 32\% PB e 3.200 kcal ED/kg; e (3) terminação: ração de 6 a $8 \mathrm{~mm}, 28 \%$ PB e $2.900 \mathrm{kcal} \mathrm{ED/kg} \mathrm{conforme} \mathrm{a} \mathrm{Tabela} 2$.

Tabela 2. Composição bromatológica das rações alternativas formuladas.

\begin{tabular}{|c|c|c|c|c|}
\hline \multirow{3}{*}{ Composição } & \multicolumn{4}{|c|}{ Tipo de Ração } \\
\hline & \multirow{2}{*}{$\begin{array}{c}\text { Inicial } \\
45 \% \text { PB } \\
3.400 \mathrm{kcal} \mathrm{ED/kg}\end{array}$} & \multicolumn{2}{|c|}{ Engorda } & \multirow{2}{*}{$\begin{array}{c}\text { Terminação } \\
28 \% \text { PB } \\
2.900 \mathrm{kcal} E D / \mathrm{kg} \\
\end{array}$} \\
\hline & & $\begin{array}{c}36 \% \text { PB } \\
3.300 \mathrm{kcal} \text { ED/kg }\end{array}$ & $\begin{array}{c}32 \% \text { PB } \\
3.200 \mathrm{kcal} \text { ED/kg }\end{array}$ & \\
\hline Energia Bruta & $4.448 \mathrm{kcal} / \mathrm{kg}$ & $4.224 \mathrm{kcal} / \mathrm{kg}$ & $4.067 \mathrm{kcal} / \mathrm{kg}$ & $3.696 \mathrm{kcal} / \mathrm{kg}$ \\
\hline Energia Digestível & $3.403 \mathrm{kcal} / \mathrm{kg}$ & $3.302 \mathrm{kcal} / \mathrm{kg}$ & $3.202 \mathrm{kcal} / \mathrm{kg}$ & $2.905 \mathrm{kcal} / \mathrm{kg}$ \\
\hline Proteína Digestível & $37,45 \%$ & $31,09 \%$ & $28,50 \%$ & $25,14 \%$ \\
\hline Proteína Bruta & $45,12 \%$ & $36,04 \%$ & $32,00 \%$ & $28,02 \%$ \\
\hline Fibra Bruta & $2,45 \%$ & $3,54 \%$ & $4,47 \%$ & $4,21 \%$ \\
\hline Extrato Etéreo & $10,83 \%$ & $7,61 \%$ & $5,32 \%$ & $2,57 \%$ \\
\hline Cálcio Total & $3,52 \%$ & $2,26 \%$ & $1,62 \%$ & $1,20 \%$ \\
\hline Fósforo Disponível & $1,54 \%$ & $1,03 \%$ & $0,79 \%$ & $0,61 \%$ \\
\hline Metionina & $0,63 \%$ & $0,41 \%$ & $0,29 \%$ & $0,25 \%$ \\
\hline Lisina & $1,13 \%$ & $0,83 \%$ & $0,67 \%$ & $0,59 \%$ \\
\hline Triptofano & $2,23 \%$ & $1,76 \%$ & $1,56 \%$ & $1,34 \%$ \\
\hline Treonina & $0,36 \%$ & $0,33 \%$ & $0,33 \%$ & $0,29 \%$ \\
\hline
\end{tabular}


Os ingredientes escolhidos para a formulação da ração alternativa foram farinha de peixe, farinha de carne, farelo de soja, farelo de trigo, fubá de milho, fosfato bicálcico, óleo de soja e sal comum, que estiveram disponíveis durante o ciclo e foram de fácil obtenção em todos os municípios, exceto a farinha de peixe que esteve disponível apenas em Belém. Outros ingredientes tiveram disponibilidade sazonal, como a farinha de pena hidrolisada, farelo de arroz e farinha de sangue.

Em relação aos equipamentos, o custo total foi estimado em $\mathrm{R} \$ 6.750,00$ baseando-se no preço de varejo, sendo o moedor elétrico e o freezer horizontal os itens mais onerosos. Ressalta-se que não foi considerada a construção de uma estrutura física para armazenamento dos ingredientes, visto que estes podem ser estocados nas mesmas condições que as rações processadas (Tabela 3).

Tabela 3. Custo dos equipamentos.

\begin{tabular}{lccccccc}
\hline \multicolumn{1}{c}{ Item } & Medida & Quant & $\begin{array}{c}\text { Valor unitário } \\
(\mathbf{R} \$)\end{array}$ & $\begin{array}{c}\text { Valor total } \\
(\mathbf{R} \$)\end{array}$ & $\%$ & $\begin{array}{c}\text { Vida útil } \\
\text { (anos) }\end{array}$ & $\begin{array}{c}\text { Depreciação } \\
\text { anual (R\$) }\end{array}$ \\
\hline Freezer 210 I & unid & 1 & $1.900,0$ & $1.900,0$ & 28,1 & 10 & 190,0 \\
Moedor elétrico & unid & 1 & $3.800,0$ & $3.800,0$ & 56,3 & 5 & 760,0 \\
Misturador 80 kg & unid & 1 & 500,0 & 500,0 & 7,4 & 5 & 100,0 \\
Lona Plástica & $\mathrm{m}^{2}$ & 25 & 2,0 & 50,0 & 0,7 & 1 & 50,0 \\
Balança 50 kg & unid & 1 & 500,0 & 500,0 & 7,4 & 5 & 100,0 \\
Outros Custos & - & - & - & 200,0 & 3,0 & - & - \\
\hline Total & - & - & - & $6.750,0$ & 100,0 & - & $1.200,0$ \\
\hline
\end{tabular}

Foi considerada a necessidade de uma pessoa como mão de obra para auxiliar na recepção dos ingredientes e processamento da ração, demandando seis diárias no primeiro semestre para a fabricação de até $1.080,0 \mathrm{~kg}$ e vinte e duas diárias para a fabricação de até $3.920,0 \mathrm{~kg}$ no segundo semestre, totalizando 28 diárias para a produção de $5.000 \mathrm{~kg}$ de ração alternativa, uma média de $180,0 \mathrm{~kg}$ por dia. No tocante ao frete de ingredientes, foi considerado o padrão de 14 viagens de até $360 \mathrm{~kg}$ (Tabela 4).

Tabela 4. Custo operacional de insumos.

\begin{tabular}{lccccc}
\hline \multicolumn{1}{c}{ Item } & Medida & Quant & Valor unitário (R\$) & Valor total (R\$) & $\%$ \\
\hline Diária & Unid & 28 & 40,0 & $1.120,0$ & 32,1 \\
Frete & Unid & 14 & 50,0 & 700,0 & 20,1 \\
Energia elétrica & - & - & 360,0 & 360,0 & 10,3 \\
Outros custos & - & - & 105,0 & 105,0 & 3,0 \\
COE & - & - & - & $2.285,0$ & 65,6 \\
Depreciação & - & - & - & $1.200,0$ & 34,4 \\
COT & - & - & - & $3.485,0$ & 100,0 \\
COT $(R \$ / k g)$ & - & & & 0,7 & - \\
\hline
\end{tabular}

As rações alternativas tiveram o custo de $R \$ 2,38, R \$ 2,17, R \$ 2,06$ e $R \$ 1,88$ por quilo produzido para os produtos com $45,36,32$ e $28 \%$ de proteína bruta, respectivamente (Tabela 5).

Tabela 5. Composição, quantidade e custo de ingredientes.

\begin{tabular}{|c|c|c|c|c|c|}
\hline \multirow{3}{*}{ Ingrediente } & \multicolumn{5}{|c|}{ Ração 45\% PB - 3.400 kcal ED/kg - Farelada (Fase Inicial) } \\
\hline & \multirow{2}{*}{$\begin{array}{c}\text { Quantidade } \\
(\%)\end{array}$} & \multirow{2}{*}{$\begin{array}{c}\text { Quantidade } \\
\text { (Saca } \sim 25 \mathrm{~kg} \text { ) }\end{array}$} & \multirow{2}{*}{$\begin{array}{c}\text { Valor unitário } \\
(\mathrm{R} \$ / \mathrm{kg})\end{array}$} & \multicolumn{2}{|c|}{ Custo } \\
\hline & & & & R\$ & $\%$ \\
\hline Farinha de peixe & 46 & 11,5 & 1,6 & 18,4 & 43,8 \\
\hline Farinha de carne & 5 & 1,3 & 1,2 & 1,5 & 3,6 \\
\hline Farelo de soja & 35 & 8,8 & 1,5 & 13,13 & 31,3 \\
\hline Fubá de milho & 3 & 0,8 & 0,9 & 0,68 & 1,6 \\
\hline Farelo de trigo & 1 & 0,3 & 0,83 & 0,21 & 0,5 \\
\hline Óleo de soja & 7 & 1,8 & 3,5 & 6,13 & 14,6 \\
\hline Fosfato bicálcico & 2,5 & 0,6 & 3 & 1,88 & 4,5 \\
\hline Sal comum & 0,5 & 0,1 & 0,5 & 0,06 & 0,2 \\
\hline Total & 100 & - & - & 41,97 & 100 \\
\hline Processamento $(\mathrm{R} \$ / \mathrm{kg})$ & - & - & - & 0,7 & - \\
\hline
\end{tabular}




\begin{tabular}{|c|c|c|c|c|c|}
\hline \multirow{3}{*}{ Ingrediente } & \multicolumn{5}{|c|}{ Ração 36\% PB - $3.300 \mathrm{kcal}$ ED/kg - 2 a 4 mm (Fase de Engorda) } \\
\hline & \multirow{2}{*}{$\begin{array}{c}\text { Quantidade } \\
(\%)\end{array}$} & \multirow{2}{*}{$\begin{array}{c}\text { Quantidade } \\
\text { (Saca } \sim 25 \mathrm{~kg} \text { ) }\end{array}$} & \multirow{2}{*}{$\begin{array}{c}\text { Valor unitário } \\
(\mathrm{R} \$ / \mathrm{kg})\end{array}$} & \multicolumn{2}{|c|}{ Custo } \\
\hline & & & & $\mathbf{R} \$$ & $\%$ \\
\hline Farinha de peixe & 20 & 5 & 1,6 & 8 & 21,8 \\
\hline Farinha de carne & 5 & 1,3 & 1,2 & 1,5 & 4,1 \\
\hline Farelo de soja & 43,5 & 10,9 & 1,5 & 16,31 & 44,4 \\
\hline Fubá de milho & 19,6 & 4,9 & 0,9 & 4,4 & 12 \\
\hline Farelo de trigo & 5 & 1,3 & 0,83 & 1,04 & 2,8 \\
\hline Óleo de soja & 4,5 & 1,1 & 3,5 & 3,89 & 10,6 \\
\hline Fosfato bicálcico & 2 & 0,5 & 3 & 1,5 & 4,1 \\
\hline Sal comum & 0,5 & 0,1 & 0,5 & 0,06 & 0,2 \\
\hline Total & 100 & - & - & 36,71 & 100 \\
\hline Processamento (R\$/kg) & - & - & - & 0,7 & - \\
\hline Total $(\mathrm{R} \$ / \mathrm{kg})$ & - & - & - & 2,17 & - \\
\hline \multirow{3}{*}{ Ingrediente } & \multicolumn{5}{|c|}{ Ração 32\% PB - $3.200 \mathrm{kcal}$ ED/kg - 4 a 6 mm (Fase de Engorda) } \\
\hline & \multirow{2}{*}{$\begin{array}{c}\text { Quantidade } \\
(\%)\end{array}$} & \multirow{2}{*}{$\begin{array}{c}\text { Quantidade } \\
\text { (Saca } \sim 25 \mathrm{~kg} \text { ) }\end{array}$} & \multirow{2}{*}{$\begin{array}{c}\text { Valor unitário } \\
(\mathrm{R} \$ / \mathrm{kg})\end{array}$} & \multicolumn{2}{|c|}{ Custo } \\
\hline & & & & $\mathbf{R} \$$ & $\%$ \\
\hline Farinha de peixe & 5 & 1,3 & 1,6 & 2 & 5,9 \\
\hline Farinha de carne & 5 & 1,3 & 1,2 & 1,5 & 4,4 \\
\hline Farelo de soja & 51,1 & 12,8 & 1,5 & 19,16 & 56,5 \\
\hline Fubá de milho & 23,8 & 6 & 0,9 & 5,36 & 15,8 \\
\hline Farelo de trigo & 10 & 2,5 & 0,83 & 2,08 & 6,1 \\
\hline Óleo de soja & 2,6 & 0,7 & 3,5 & 2,28 & 6,7 \\
\hline Fosfato bicálcico & 2 & 0,5 & 3 & 1,5 & 4,4 \\
\hline Sal comum & 0,5 & 0,1 & 0,5 & 0,06 & 0,2 \\
\hline Total & 100 & - & - & 33,93 & 100 \\
\hline Processamento (R\$/kg) & - & - & - & 0,7 & - \\
\hline Total $(\mathrm{R} \$ / \mathrm{kg})$ & - & - & - & 2,06 & - \\
\hline
\end{tabular}

\begin{tabular}{|c|c|c|c|c|c|}
\hline \multirow{3}{*}{ Ingrediente } & \multicolumn{5}{|c|}{ Ração $28 \%$ PB - $2.900 \mathrm{kcal}$ ED $/ \mathrm{kg}$ - 6 a $8 \mathrm{~mm}$ (Fase de Terminação) } \\
\hline & \multirow{2}{*}{$\begin{array}{c}\text { Quantidade } \\
(\%)\end{array}$} & \multirow{2}{*}{$\begin{array}{l}\text { Quantidade } \\
\text { (Saca } \sim 25 \mathrm{~kg} \text { ) }\end{array}$} & \multirow{2}{*}{ Valor unitário $(R \$ / k g)$} & \multicolumn{2}{|c|}{ Custo } \\
\hline & & & & $\mathbf{R} \mathbf{S}$ & $\%$ \\
\hline Farinha de peixe & 3,5 & 0,9 & 1,6 & $\overline{1,4}$ & 4,7 \\
\hline Farinha de carne & 3 & 0,8 & 1,2 & 0,9 & 3,1 \\
\hline Farelo de soja & 45 & 11,3 & 1,5 & 16,88 & 57,2 \\
\hline Fubá de milho & 30,5 & 7,6 & 0,9 & 6,86 & 23,2 \\
\hline Farelo de trigo & 10 & 2,5 & 0,83 & 2,08 & 7 \\
\hline Óleo de soja & 0 & 0 & 3,5 & 0 & 0 \\
\hline Fosfato bicálcico & 1,8 & 0,5 & 3 & 1,35 & 4,6 \\
\hline Sal comum & 0,5 & 0,1 & 0,5 & 0,06 & 0,2 \\
\hline Sabugo & 5,7 & 1,4 & 0 & 0 & 0 \\
\hline Total & 100 & - & - & 29,53 & 100 \\
\hline Processamento (R\$/kg) & - & - & - & 0,7 & - \\
\hline Total $(\mathrm{R} \$ / \mathrm{kg})$ & - & - & - & 1,88 & - \\
\hline
\end{tabular}

Verificou-se que o preço médio das rações industrializadas por quilo foi de $R \$ 4,50$ (45\% $P B), R \$ 3,12$ (36\% PB), R\$ 2,60 (32\% PB) e R $\$ 2,16(28 \%$ PB) e, segundo a QR por tipo (Tabela 1), o custo por fase de crescimento foi de $R \$ 81,00, R \$ 348,19, R \$ 716,04$ e $R \$ 6.901,20$, resultando no desembolso de $R \$ 8.046,43$ por 3,6 toneladas de ração. Ao atribuir estes custos às rações alternativas, isto é, ao correlacionarmos com o preço por quilo mensurou-se a quantidade destas para as fases de crescimento e a conversão alimentar aceitável, isto é, o consumo de ração alternativa máximo a um igual desembolso (Tabela 6). 
Tabela 6. Comparativo de preço, quantidade e conversão alimentar entre ração industrializada e alternativa.

\begin{tabular}{|c|c|c|c|c|c|c|c|c|}
\hline \multirow{3}{*}{ Características } & \multicolumn{8}{|c|}{ Rações } \\
\hline & \multicolumn{2}{|c|}{$45 \%$ PB } & \multicolumn{2}{|c|}{$36 \%$ PB } & \multicolumn{2}{|c|}{$32 \%$ PB } & \multicolumn{2}{|c|}{$28 \%$ PB } \\
\hline & Ind. ${ }^{1}$ & Alt. $^{2}$ & Ind. & Alt. & Ind. & Alt. & Ind. & Alt. \\
\hline Preço da & 4,5 & 2,38 & 3,12 & 2,17 & 2,6 & 2,06 & 2,16 & 1,88 \\
\hline Quantidade de ração estimada $(\mathrm{kg})$ & 18 & 34 & 111,6 & 160,5 & 275,4 & 347,6 & 3195 & $3.670,9$ \\
\hline Conversão alimentar estimada & 1 & 1,9 & 1,2 & 1,8 & 1,7 & 2,1 & 2,2 & 2,4 \\
\hline
\end{tabular}

${ }^{1}$ Ind. = industrializada; ${ }^{2}$ Alt. = alternativa.

A conversão alimentar para as rações alternativas ao final do ciclo de produção pretendido (12 meses) foi de 2,3:1 e um valor superior a este inviabilizaria financeiramente seu uso por parte dos piscicultores, pois o seu custo seria maior que o desembolso para aquisição de rações industrializadas. Ressalta-se que foi possível obter maior quantidade de ração artificial em detrimento da ração industrializada e com informação nutricional semelhante (Tabela 7).

Tabela 7. Custo e conversão alimentar de ração industrializada e alternativa.

\begin{tabular}{lccccc}
\hline Rações & $\begin{array}{c}\text { Tempo de utilização } \\
\text { (dias) }\end{array}$ & Biomassa (kg) & \multicolumn{2}{c}{ Quantidade de ração (kg) } & \multirow{2}{*}{$\begin{array}{c}\text { Custo com ração } \\
\text { Ind }^{2}\end{array}$} \\
\hline $45 \%$ PB & 30 & 18 & 18 & 34 & 81,00 \\
$36 \%$ PB & 60 & 153 & 111,6 & 160,5 & 348,19 \\
$32 \%$ PB & 60 & 450 & 275,4 & 347,6 & 716,04 \\
$28 \%$ PB & 215 & 1.530 & 3.195 & $3.670,9$ & $6.901,20$ \\
\hline Total & 365 & 1.800 & 3.600 & 4.213 & $8.046,43$ \\
\hline CAA & - & - & 2,1 & 2,3 & - \\
\hline
\end{tabular}

${ }^{1}$ Custo padronizado para aquisição das respectivas quantidades de rações industrializada e alternativa segundo o teor de proteína bruta (PB); ${ }^{2}$ Ind. = industrializada; ${ }^{3}$ Alt. = alternativa.

\section{Discussão}

Para a formulação correta da ração é necessário estudar o animal para identificar as exigências nutricionais a serem atendidas. Assim, várias informações devem ser consideradas, como: espécie, idade, peso, sexo, etc (Cardinal, Costa \& Ribeiro, 2019). Nesse sentido, foi considerado o tambaqui C. macropomum como representante de peixes onívoros por apresentar vasta literatura sobre seu hábito alimentar e nutrição em ambientes de cultivo, bem como ser espécie nativa da região de estudo e uma das mais cultivadas. Além disso, dentre suas características, apresenta bom desempenho zootécnico em ambientes de criação e a fácil adaptação à dieta com rações. Ela pode ser suplementar, quando se deseja aproveitar o alimento natural, ou balanceada, quando lhe ofertamos nutrientes essenciais segundo sua demanda biológica, que foi o propósito deste estudo no intuito de diminuir os custos por meio da substituição total de rações industrializadas por rações alternativas peletizadas (Moro \& Rodrigues, 2015).

Observou-se que a aquisição de ingredientes no varejo elevou o custo de produção e uma alternativa para diminuí-lo seria estocar maior volume de ingredientes por meio da aquisição via atacado, porém isso aumentaria o custo de implantação e logística, sendo pouco viável para pequenos produtores já que o armazenamento influencia o preço final das rações (Cyrino, Carneiro, Bozano \& Caseiro, 1998).

A vantagem da formulação proposta foi a presença de corpo técnico especializado composto de um profissional, excetuando-se a mão-de-obra auxiliar, além de processamento, controle de qualidade, custos operacionais e transporte eficientes e de baixo custo, todos fatores que compõe a flutuação de preço das rações comumente comercializadas. $O$ ingrediente também foi fator que o influenciou, principalmente commodities como milho e soja por serem mais onerosas e representarem maior parte da composição de rações (Schmidt, Zanotto, Junior \& Scheuermann, 2017).

A farinha de peixe, a farinha de carne, o farelo de soja, o farelo de trigo, o fubá de milho, o fosfato bicálcico, óleo de soja e sal comum também são utilizados pelas indústrias e podem ser considerados tradicionais na formulação de rações, devido talvez pela facilidade de aquisição. Por outro lado, a farinha de pena hidrolisada, farelo de arroz e farinha de sangue são ingredientes sujeitos às criações e cultivos que lhe originam e ao processo para se obter as matérias-primas, logo, poderiam ser substituídas por outras equivalentes (Sonoda, França \& Cyrino, 2016 apud Ono, 1988). 
A ausência de antioxidantes, aminoácidos sintéticos e de premix vitamínico/mineral se deu pela baixa disponibilidade dos produtos nos municípios analisados e essa ausência pode diminuir a vida útil das rações após o processamento, exigindo equilíbrio entre fabricação e consumo. Ressalta-se que não foi considerado o processo de extrusão para ração alternativa devido ao elevado custo do equipamento (extrusora), o que pode contribuir para a perda de ração e deposição de matéria orgânica no ambiente de cultivo. Salienta-se que a qualidade do manejo alimentar define a severidade do impacto ambiental da piscicultura no que se refere aos efluentes (Cyrino et al., 2010).

Ressalta-se também que o processamento das rações deve ser criterioso desde a moagem até as etapas finais, isso pode ser determinante no aproveitamento dos nutrientes pelos peixes e, ao final do processo, devem ser observados parâmetros como coloração, quantidade de finos, uniformidade dos péletes e cheiro, que são características complementares para se verificar a qualidade do alimento. Assim, a escolha dos fornecedores de ingredientes é fundamental na eficiência da produção da ração a ser ofertada aos peixes (Ribeiro et al., 2012).

\section{Conclusão}

As rações alterativas apresentam menor preço por quilo em relação às rações industrializadas, sendo mais acessível financeiramente. Porém, o investimento inicial pode ser um problema em empreendimentos de menor porte devido ao preço relativamente elevado de alguns equipamentos que são necessários para esta finalidade. A ração alternativa necessita ser testada para verificar seu desempenho no crescimento de peixes onívoros.

\section{Referências}

Brabo, M.F., Dias, B., Santos, L., Ferreira, L., Veras, G., Chaves, R. (2014). Competitividade da cadeia produtiva da piscicultura no Nordeste paraense sob a perspectiva dos extensionistas rurais. Informações Econômicas, 44 (5), 1-13.

Brabo, M.F., Flexa, C.C.E., Veras, G.C.G., Paiva, R.S., Fujimoto, R.Y. (2013). Viabilidade econômica da piscicultura em tanques-rede no reservatório da usina hidrelétrica de tucuruí, estado do Pará. Informações Econômicas, 43 (3), 56-64.

Brabo, M.F., Veras, G.C., Campelo, D.A.V., Paixão, D.J.M.R., Costa, M.W.M. (2016). Piscicultura no Estado do Pará: planejamento e estratégias de produção [Versão digital].

Cardinal, K.M., Costa, J.L.B., Ribeiro, A.M.L. (2019). Princípios básicos na formulação de rações. PubMed, 13 (9), 1-7. doi: 10.31533/pubvet.v13n9a410.1-7

Cyrino, J.E.P., Bicudo, A.D.A., Sado, R.Y., Borghesi, R., Dairiki, J.K. (2010). A piscicultura e o ambiente: o uso de alimentos ambientalmente corretos em piscicultura. Revista Brasileira de Zootecnia, 39 (1), 68-87. doi:10.1590/S1516-35982010001300009

Cyrino, J.E.P., Carneiro, P.C.F., Bozano, G.L.N., Caseiro, A.C. (1998). Desenvolvimento da criação de peixes em tanques-rede: Uma análise dos fundamentos, viabilidade e tendências, baseada em experiências bemsucedidas no Sudeste do Brasil. In Anais do Simpósio Brasileiro de Aquicultura X (p. 409). Recife, PE.

Dairiki, J.K., Da Silva, T.B.A. (2011). Revisão de literatura: exigências nutricionais do tambaqui-compilação de trabalhos, formulação de ração adequada e desafios futuros [Versão digital].

Furuya, W.M., Pezzato, L.E., Barros, M.M., Boscolo, W.R., Cyrino, J.E.P., Furuya, V.R.B., Feiden, A. (2010). Tabelas brasileiras para a nutrição de tilápias. Toledo, PR.

Izel, A.C.U., Melo, L.A.S. (2004). Criação de tambaqui (Colossoma macropomum) em tanques escavados no Estado do Amazonas [Versão digital].

Kubitza, F. (2009). Manejo na produção de peixes. Panorama da Aquicultura, 19 (111), 14-27.

Macedo, C.F., Sipaúba-Tavares, L.H. (2018). Eutrofização e qualidade da água na piscicultura: consequências e recomendações. Boletim do instituto de Pesca, 36 (2), 149-163. 




Matsunaga, M., Bemelmans, P.F., Toledo, P. (1976). Metodologia de custo de producao utilizada pelo IEA. Agricultura em Sao Paulo. 23 (1),123-139.

Moro, G.V., Rodrigues, A.P.O. (2015). Rações para organismos aquáticos: tipos e formas de processamento [Versão digital].

Oliveira, R. (2015). O panorama da aquicultura no Brasil: a prática com foco na sustentabilidade. Revista Intertox de Toxicologia, Risco Ambiental e Sociedade, 2 (1), 71-89. doi: 10.22280/revintervol2ed1.18

Ribeiro, P.A.P., Melo, D., Costa, L.S., Teixeira, E. (2012). Manejo nutricional e alimentar de peixes de água doce [Versão digital].

Salaro, A.L. (2009). Manejo e nutrição de peixes em tanques-rede [Versão digital].

Schmidt, G.S., Zanotto, D.L., Junior, A.C., Scheuermann, G.N. (2017). Impacto econômico do ajuste da energia metabolizável do milho na formulação de rações de frango de corte. In Anais do Seminário técnico científico de aves e suínos XVI (p. 1). Florianópolis, SC.

Sonoda, D.Y., França, E.D., Cyrino, J.E.P. (2016). Modelo de preço de ração para peixe no período de 2001 a 2015. Revista iPegece, 2 (3), 57-51. doi: 10.22167/r.ipecege.2016.3.57

Ono, E.A. (1998). Formação de preços das rações comerciais para peixes. In Anais do Simpósio Sobre Manejo e Nutrição de Peixes /I ( p. 172). Campinas, SP. 